\title{
Transcriptional activation of the Axl and PDGFR- $\alpha$ by c-Met through a ras- and Src-independent mechanism in human bladder cancer
}

\author{
Chen-Yun Yeh', Shin-Mei Shin ${ }^{1}$, Hsuan-Heng Yeh ${ }^{3}$, Tsung-Jung Wu², Jyh-Wei Shin ${ }^{4}$, Tsuey-Yu Chang ${ }^{4}$, \\ Giri Raghavaraju', Chung-Ta Lee ${ }^{2}$, Jung-Hsien Chiang ${ }^{5}$, Vincent S Tseng ${ }^{5}$, Yuan-Chii G Lee ${ }^{7}$, Cheng-Huang Shen ${ }^{8}$, \\ Nan-Haw Chow ${ }^{2,6+}$ and Hsiao-Sheng Liu ${ }^{1,6^{*+}}$
}

\begin{abstract}
Background: A cross-talk between different receptor tyrosine kinases (RTKs) plays an important role in the pathogenesis of human cancers.

Methods: Both NIH-Met5 and T24-Met3 cell lines harboring an inducible human c-Met gene were established. CMet-related RTKs were screened by RTK microarray analysis. The cross-talk of RTKs was demonstrated by Western blotting and confirmed by small interfering RNA (siRNA) silencing, followed by elucidation of the underlying mechanism. The impact of this cross-talk on biological function was demonstrated by Trans-well migration assay. Finally, the potential clinical importance was examined in a cohort of 65 cases of locally advanced and metastatic bladder cancer patients.

Results: A positive association of Axl or platelet-derived growth factor receptor-alpha (PDGFR- $\alpha$ ) with c-Met expression was demonstrated at translational level, and confirmed by specific siRNA knock-down. The transactivation of c-Met on Axl or PDGFR- $\alpha$ in vitro was through a ras- and Src-independent activation of mitogenactivated protein kinase/extracellular signal-regulated kinase (MEK/ERK) pathway. In human bladder cancer, coexpression of these RTKs was associated with poor patient survival $(p<0.05)$, and overexpression of c-Met/Axl/ PDGFR- $\alpha$ or c-Met alone showed the most significant correlation with poor survival $(p<0.01)$.

Conclusions: In addition to c-Met, the cross-talk with AxI and/or PDGFR- $\alpha$ also contributes to the progression of human bladder cancer. Evaluation of AxI and PDGFR- $\alpha$ expression status may identify a subset of c-Met-positive bladder cancer patients who may require co-targeting therapy.
\end{abstract}

Keywords: Axl PDGFR-a, c-Met, bladder cancer

\section{Background}

The RTK c-Met is expressed during normal development and plays a crucial role in many cell regulatory processes [1]. After binding to its cognate ligand-hepatocyte growth factor (HGF), activated c-Met transmits signals implicated in the cell proliferation, motility, survival, and morphogenesis [2-4]. C-Met is over-expressed and usually associated with metastatic progression of a

\footnotetext{
* Correspondence: a713@mail.ncku.edu.tw

+ Contributed equally

'Department of microbiology and immunology, College of medicine,

National Cheng Kung University, Tainan, Taiwan

Full list of author information is available at the end of the article
}

variety of human malignant tumors, including bladder cancer $[1,5]$. We have reported that $\mathrm{c}$-Met is overexpressed in $32.3 \%, 63.2 \%$, and $65.2 \%$ of superficial, locally advanced and metastatic bladder cancer, respectively [6]. Over-expression of c-Met is positively associated with muscle invasion and poor long term survival $(\mathrm{p}<0.001)$, while it is not related to patient outcome in the subset of superficial bladder cancer. Miyata et al. also reported the significance of c-Met in bladder cancer development and as an important predictor of metastasis and patient survival [7]. Therefore, c-Met is emerging as a novel therapeutic target in many solid tumors [8-10].

\section{C) Biomed Central}


Dimerization is generally required for activating RTKs [11]. In addition to heterodimeric complex formation of the same subfamily [6,11-14], heterologous RTK interaction is also involved in the pathogenesis of human cancers, e.g. between EGFR and RON (a member of the cMet family) $[15,16]$. The biological significance of inhibition of both RTK signaling pathways of cancer cells was demonstrated in the context of cell proliferation, migration, anti-apoptosis and transformation in vitro. [15]. Therefore, identification of cross-talk partners of c-Met involved in the tumorigenesis may provide important biomarkers for co-targeting therapy. In our prior RTK profiling experiment, c-Met was frequently co-expressed with Axl, platelet-derived growth factor receptor $\alpha$ (PDGFR- $\alpha$ ), DDR2 and/or IGF1R in the same uroepithelial cells [17], suggesting the existence of yet unspecified cross-talk partners of c-Met.

Axl overexpression is detected in various human cancers, and is associated with invasiveness and/or metastasis of carcinoma of the breast [18], stomach [19], kidney [20], lung [21], and prostate [22]. High expression of PDGFR $-\alpha$ is also detected in a variety of tumors, such as prostatic intraepithelial neoplasia, and carcinoma of the ovary, kidney, breast and liver [23-26]. Furthermore, PDGFR- $\alpha$ expression provides additional predictive value related to breast cancer progression [23], and patient's survival in the kidney cancer [27] or lung cancer [28]. The implications of these two receptor-related signaling events in the bladder carcinogenesis, however, remain unclear. This study was aimed to identify the novel interaction partners of c-Met, investigate their regulation, effect on biological activity, and the potential significance in association with patient outcome.

\section{Methods}

Cell Lines, transfection, and stable cell line establishment $\mathrm{NIH} / 3 \mathrm{~T} 3$ mouse fibroblast cell line and bladder cancer cell line T24 were obtained commercially. The four bladder cancer cell lines UB09: stage B2; UB40: stage A, papillary; UB47: stage B1; TSGH8301: stage A were established from patients of transitional cell carcinoma of the urinary tract [6,29]. UB47 was cultured in RPMI medium 1640 supplemented with $15 \%$ fetal bovine serum (FBS). Other cell lines were cultured in Dulbecco's modified Eagle's medium (DMEM) supplemented with 10\% FBS.

The plasmids pTRE-Met and pTet-Lac-Hyg were transfected into NIH/3T3 and T24 cells by Lipofectamine $^{\mathrm{TM}} 2000$ reagent according to manufacturer's protocol (Invitrogen, Carlsbad, CA, USA) [30]. Two stable cell lines: NIH-Met5 and T24-Met3 were established.

\section{Microarray array}

RNA was isolated using TRIzol reagent (GIBCO BRL, Gaithersburg, MD, USA), followed by mRNA purification using Oligotex ${ }^{\mathrm{TM}}$ mRNA kit (Qiagen, Valencia, CA, USA). RNA samples were reverse transcribed into cDNA fluorescently labeled either with Cy3 or with Cy5. The labeled cDNA was hybridized with a microarray cDNA chip containing 192 RTK genes [31]. Data were imported and normalized using MeV: MultiExperiment Viewer (DanaFarber Cancer Institute, http://www.tm4.org/mev.html) [32]. Clustering affinity search technique (CAST) was used for gene expression cluster analysis. There are 23 clusters after CAST analysis [33], the gene expression profiles of 8 genes showing the best correlation with c-Met gene were clustered as one group (table 1).

\section{Antibodies}

Anti-phospho-tyrosine antibody was purchased from BD Transduction Laboratories (Lexington, KY, USA), and antibodies to Axl, c-Met, p-Met (phosphorylation of cMet;Tyr 1234), PDGFR- $\alpha$, and p-PDGFR- $\alpha$ (phosphorylation of PDGFR- $\alpha$; Tyr 754) were purchased from Santa Cruz Biotechnology (Santa Cruz, CA, USA). The Ras antibody was obtained from Calbiochem (Merck, Darmstadt, Germany), Sp1 from Upstate Biotechnology Inc. (Golden, CO, USA), p-Axl (phosphorylation of Axl;Tyr 702) from Cell Signaling Technology Inc. (Beverly, MA, USA) and $\beta$-actin was purchased from Sigma-Aldrich (St. Louis, MO, USA). The Src antibody was obtained from Millipore (Billerica, MA, USA) and p-Src (phosphorylation of Src; Tyr 418) purchased from Invitrogen (Carlsbad, CA, USA).

\section{Western blot analysis}

The western blot analysis was performed as previously described [6]. Briefly, the total lysates were prepared using RIPA solution. Total protein $(50 \mu \mathrm{g})$ was analyzed by polyacrylamide gel electrophoresis and transferred to the PVDF membrane. The membrane was probed with targeted protein antibodies and the immune complex was detected with an enhanced chemiluminescence

\begin{tabular}{|c|c|c|c|c|}
\hline $\begin{array}{c}\text { RTK } \\
\text { name }\end{array}$ & $\begin{array}{c}\mathrm{NIH} / \\
3 \mathrm{~T} 3\end{array}$ & $\begin{array}{c}\text { NIH-Met5 day } \\
1\end{array}$ & $\begin{array}{c}\text { NIH-Met5 day } \\
4\end{array}$ & $\begin{array}{c}\text { NIH-Met5 day } \\
7\end{array}$ \\
\hline$A x I$ & -0.43 & 1.48 & -0.71 & -0.34 \\
\hline ERBB2 & -0.24 & 1.34 & -1.07 & -0.02 \\
\hline ERBB3 & -0.34 & 1.47 & -0.79 & -0.35 \\
\hline Met & 0.02 & 1.18 & -1.26 & 0.06 \\
\hline MST1R & -0.35 & 1.45 & -0.84 & -0.26 \\
\hline PDGFR $\alpha$ & -0.40 & 1.48 & -0.70 & -0.38 \\
\hline PDGFR $\beta$ & -0.20 & 1.13 & -1.25 & 0.32 \\
\hline TIE1 & -0.24 & 1.47 & -0.76 & -0.47 \\
\hline TIE2 & -0.01 & 1.38 & -0.97 & -0.40 \\
\hline
\end{tabular}


(ECL) detection system (Perkin Elmer Life Sciences, USA).

\section{siRNA transfection}

Specific siRNA sense sequences were as follows: c-Met siRNA: 5'-AAGTGCAGTATCCTCTGACAG-3`, Axl siRNA: $5^{`}$-CGTGGAGAACAGCGAGATTTA-3`, and PDGFR $\alpha$ siRNA: $5{ }^{`}$-CGAGACGATTGATGCAGGATA-3 . The cells $\left(5 \times 10^{5}\right)$ were seeded into a 6 -cm cell culture dish and incubated in DMEM medium without antibiotics. Lipofectamine 2000 reagent $(10 \mu \mathrm{l})$ was diluted in $500 \mu \mathrm{l}$ of DMEM serum-free media and incubated for $5 \mathrm{~min}$ at RT. The siRNA was diluted in $500 \mu \mathrm{l}$ of DMEM serum-free medium to the assigned concentrations. Mock transfection was conducted in parallel using distilled water as the negative control. Then cells were incubated at $37^{\circ} \mathrm{C}$ in the $5 \% \mathrm{CO}_{2}$ incubator for 4 $\mathrm{h}$. The media were replaced with normal media and cells were incubated for additional $48 \mathrm{~h}$ before protein extraction.

\section{Trans-well migration assay}

The effect of RTK cross-talk on cell migration was analyzed in TSGH8301 bladder cancer cells using a 24-well Transwell ${ }^{\mathrm{TM}}$ system (Corning inc., Lowell, MA). Briefly, cells were cultured in a $6-\mathrm{cm}$ plate and transfected with c-Met, Axl, or PDGFR- $\alpha$ siRNA for $24 \mathrm{~h}$, respectively. Then, cells were resuspended with serum-free medium and added into the upper chamber of the trans-well insert $\left(2 \times 10^{5}\right.$ cells/well $)$. The $10 \%$ FBS-containing DMEM was added in the lower chamber. Cells were incubated $\mathrm{h}$ at $37^{\circ} \mathrm{C}$ for $36 \mathrm{~h}$. Migrated cells were fixed with $4 \%$ formaldehyde in PBS and stained with $2 \%$ crystal violet in $2 \%$ ethanol. The non-migrated cells in the upper chamber were removed by wiping with a cotton swab. The cells on the lower surface of the filter, representing migration of the cells through the membrane, were counted under a light microscope.

\section{Clinicopathological characteristics of study cases}

Since c-Met is important in the progression of bladder cancer, both locally advanced and metastatic bladder tumors were recruited to evaluate the significance of coexpression patterns of c-Met and other RTKs. Archival material of 65 patients ( 44 men and 21 women; age range, 40 to $84 \mathrm{yr}$ old; mean $\pm \mathrm{SD}, 61.5 \pm 9.4 \mathrm{yrs}$ ) with locally advanced or metastatic urothelial bladder cancer (21pT2, 27pT3, 17pT4) was analyzed for RTK expression. These patients were diagnosed and treated in the National Cheng Kung University Hospital, Tainan, Taiwan, between 1990 and 1999 years. The numbers with low or high grade urothelial carcinoma were 20 and 45 , respectively, according to definitions described previously [34]. Seven patients received partial cystectomy and remaining fifty-eight patients received radical cystectomy and bilateral pelvic lymph node dissection. Among them, 23 (35.4\%) patients had pelvic lymph node involvement. An adjuvant systemic chemotherapy, including methotrexate, vinblastine, epirubicin, and cisplatin (M-VEC regimen), was given to 20 patients (30.8\%) after radical cystectomy. The survival status was determined by outpatient clinic records and/or confirmed by interview with patients' families. Clinical follow-up ranged from 26 to 140 months (mean \pm SD: $50.02 \pm 6.46$ months). The time of the first tumor recurrence and for disease specific survivals were counted. The time is calculated until the death of the patient due to bladder cancer. Patients who died of other causes or were still alive at the last follow-up were censored.

\section{Immunohistochemical staining}

Immunostaining procedures were described in detail previously [6]. Briefly, tissue sections were incubated at RT for $2 \mathrm{~h}$ with monoclonal anti-cMet (1:100 dilution; Santa Cruz), anti-AXL (1:10 dilution; Santa Cruz) and anti-PDGFR- $\alpha$ (1:200 dilution; Santa Cruz) antibodies raised against the membrane protein. The optimal dilution was determined by using human kidney as a positive control [5]. Then StrAviGen Super Sensitive MultiLink kit (BioGenex Laboratories, Inc., San Ramon, California) was used to detect the resulting immune complex. Peroxidase activity was visualized using an aminoethyl carbazole substrate kit (Zymed Laboratories, Inc., San Francisco, Califonia).

Because no apparent difference of staining intensity was detected, only the proportion of tumor cells stained for c-Met, Axl or PDGFR- $\alpha$ was considered in classification [6]. "High level of expression" indicates $>50 \%$ of the tumor cells were immunostained, "low level of expression" indicates 10\%-50\% reactivity; and "negative" indicates $<10 \%$ staining for RTK protein.

\section{Statistical analysis}

The association between tumor staging or gross characteristics with expression status of c-Met, Axl, and PDGFR- $\alpha$ was analyzed by Chi-square test as appropriate. The correlation between co-expression patterns of RTKs and disease-specific survival of cancer patients was constructed according to Kaplan-Meier method by Log rank test.

\section{Results}

Establishment of stable cell lines harboring inducible cMet gene

Two stable cell lines, designated as NIH-Met5 (mouse fibroblast) and T24-Met3 (human bladder cancer cell), were established to harbor the inducible c-Met gene, which was expressed only in the absence of tetracycline 
(Tet) (Figure 1A, lane 3 and 4; Figure 1B, lane 1). When c-Met was over-expressed, the increase of its phosphorylated form ( $\mathrm{p}$-Met) indicates an auto-phosphorylation (Figure 1A, lane 3; Additional file 1, lane 6). Expression of p-Met was further enhanced 10 min after treatment with hepatocyte growth factor (HGF; Sigma, St. Louis, MO, USA) (Figure 1A, lane 4; Additional file 1, lane 7). In contrast, parental NIH/3T3 cells did not express cMet and p-Met (Figure 1A, lanes 1 and 2; Additional file 1 , lane4 1-4). It is interesting to note that c-Met or p-Met was not expressed in NIH-Met5 cells when treated with Tet alone or combined with HGF treatment (Figure 1A, lanes 5 and 6; Additional file 1, lanes 8-9). Concerning T24-Met3 cells, expression of c-Met was suppressed $24 \mathrm{~h}$ after treatment with Tet (Figure 1B, lane 2). Together, auto-phosphorylation occurred when c-Met was over-expressed, and HGF treatment further enhanced the phosphorylation of c-Met. The results demonstrate a successful in vitro model in modulating the expression of c-Met using Tet-off system.

\section{Expression and functional association of c-Met with AxI} and PDGFR- $\alpha$ in vitro

To identify the novel interaction partners of c-Met, $\mathrm{NIH}-$ Met5 cells were first treated with Tet for $24 \mathrm{~h}$, and then cultured in the absence of Tet for an additional 4 and 7 days (Figure 2A), respectively. Total RNA was extracted and subjected to screening using a cDNA microarray as previously described [35]. Among 192 RTKs, a total of 8 genes were positively correlated with c-Met over-expression, including Axl, PDGFR- $\alpha$, PDGFR- $\beta$, ERBB2, ERBB3, MST1R, TIE1 and TIE2 (table 1). One of these candidate genes-MST1R was recently reported in our laboratory [6]. In addition, coexpression of c-Met with Axl and/or PDGFR- $\alpha$ was also detected in our pilot molecular profiling of RTKs in human bladder cancer cells in vitro [16]. As a result, both Axl and PDGFR- $\alpha$ were chosen for subsequent analysis. The comparable expression patterns of c-Met, Axl and PDGFR- $\alpha$ at RNA level were shown in Figure 2A.

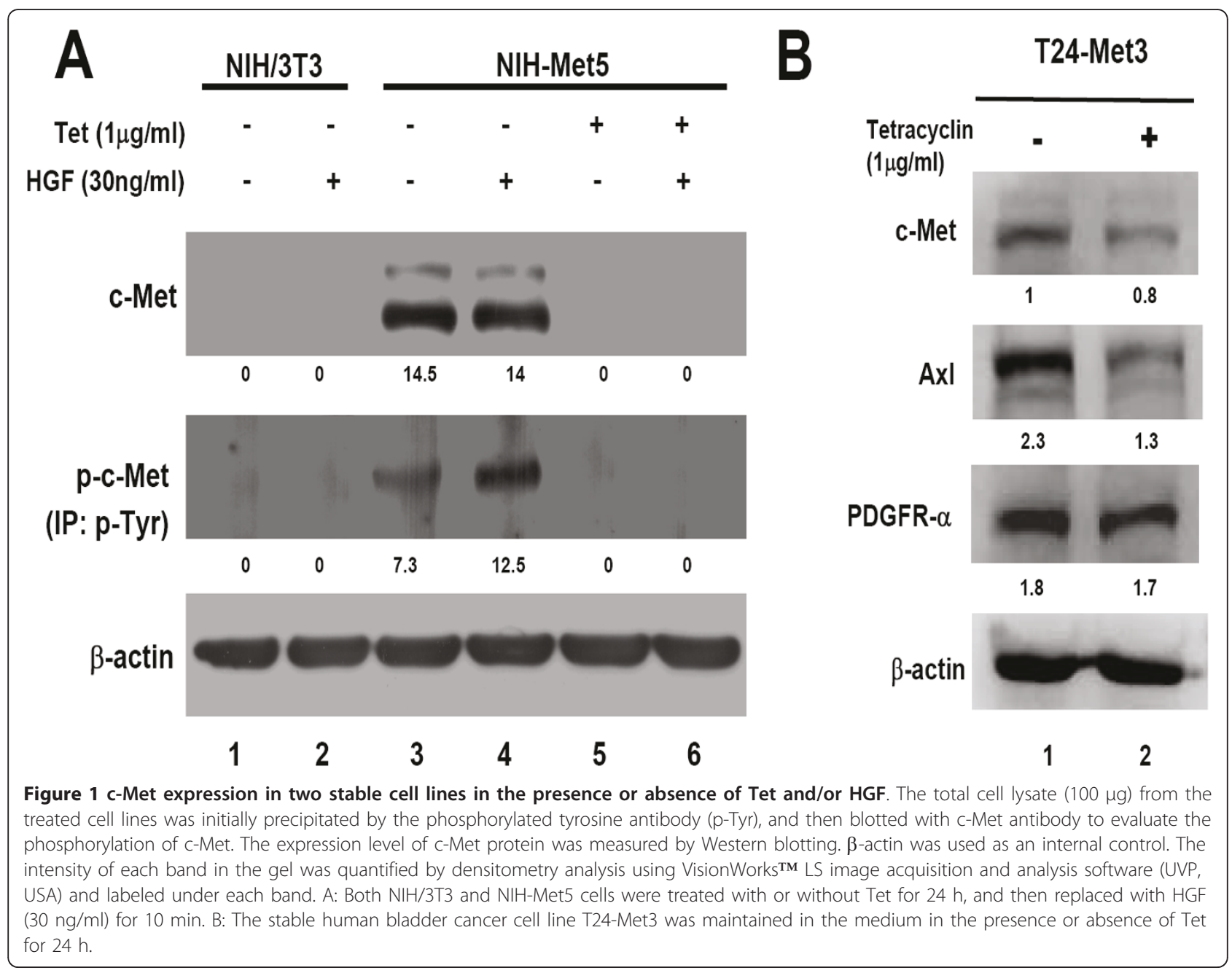




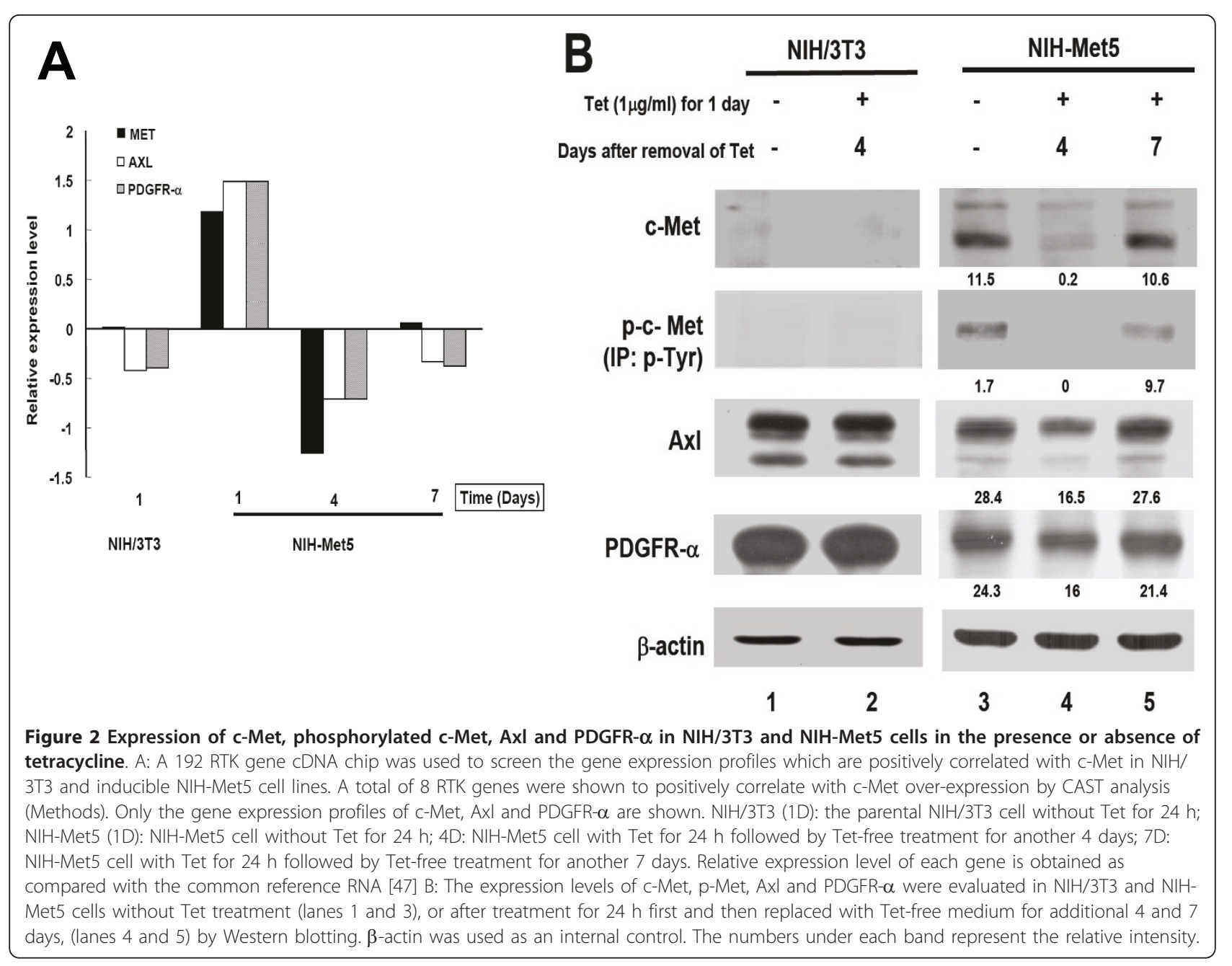

The regulation was then examined at protein level in NIH-Met5 cells. As shown in figure 2B (lane 3), c-Met was overexpressed in the absence of Tet, while suppressed c-Met expression was demonstrated after treatment of Tet for $24 \mathrm{~h}$, as with that of figure 1. A reversion of c-Met expression gradually appeared after removal of Tet for 4 and 7 days. Expression of c-Met became visible by day 4 and almost completely reversed by day 7 after removal of Tet (Figure 2B, lanes 4 and 5 ). The parental NIH/3T3 cells were used as a control (Figure $2 \mathrm{~B}$, lanes 1 and 2 ).

Using total c-Met and p-Met as the reference, expression of Axl and PDGFR- $\alpha$ showed a comparable trend to that of c-Met at day 4 and day 7 (Figure 2B, lanes 4 $5)$, respectively. This positive association of Axl or PDGFR- $\alpha$ with c-Met expression was also demonstrated in T24-Met3 human bladder cancer cell line (Figure 1B). However, no difference of Axl and PDGFR- $\alpha$ expression was detected in NIH3T3 cells (Figure 2B, lanes 1 and 2). Taken together, expression patterns of total c-Met and p-Met were positively correlated with
Axl and PDGFR- $\alpha$ expression, suggesting a functional relationship between Axl/PDGFR- $\alpha$ and c-Met.

\section{Correlation of c-Met expression with AxI and PDGFR- $\alpha$ status in human bladder cancer cells}

Both UB40 and UB47 are two bladder cancer cell lines established locally from primary bladder cancer of superficial and muscle-invasive type, respectively [6]. Apparent expression of c-Met and p-Met protein was detected in these two cell lines, and both Axl and PDGFR- $\alpha$ also showed a comparable expression pattern (Figure 3A). To confirm their functional interaction, these cell lines were maintained under serum starvation for $12 \mathrm{~h}$, and then treated with HGF (30 $\mathrm{ng} / \mathrm{ml}$ ) for $10 \mathrm{~min}$ (Figure 3A). Up-regulation of Axl and PDGFR- $\alpha$ was demonstrated in UB40 and UB47 cells after HGF stimulation with a corresponding increase of p-Met (Figure 3A). Level of p-Met positively correlated with the expression of Axl and PDGFR- $\alpha$, suggesting a relationship among c-Met, Axl and PDGFR- $\alpha$. 


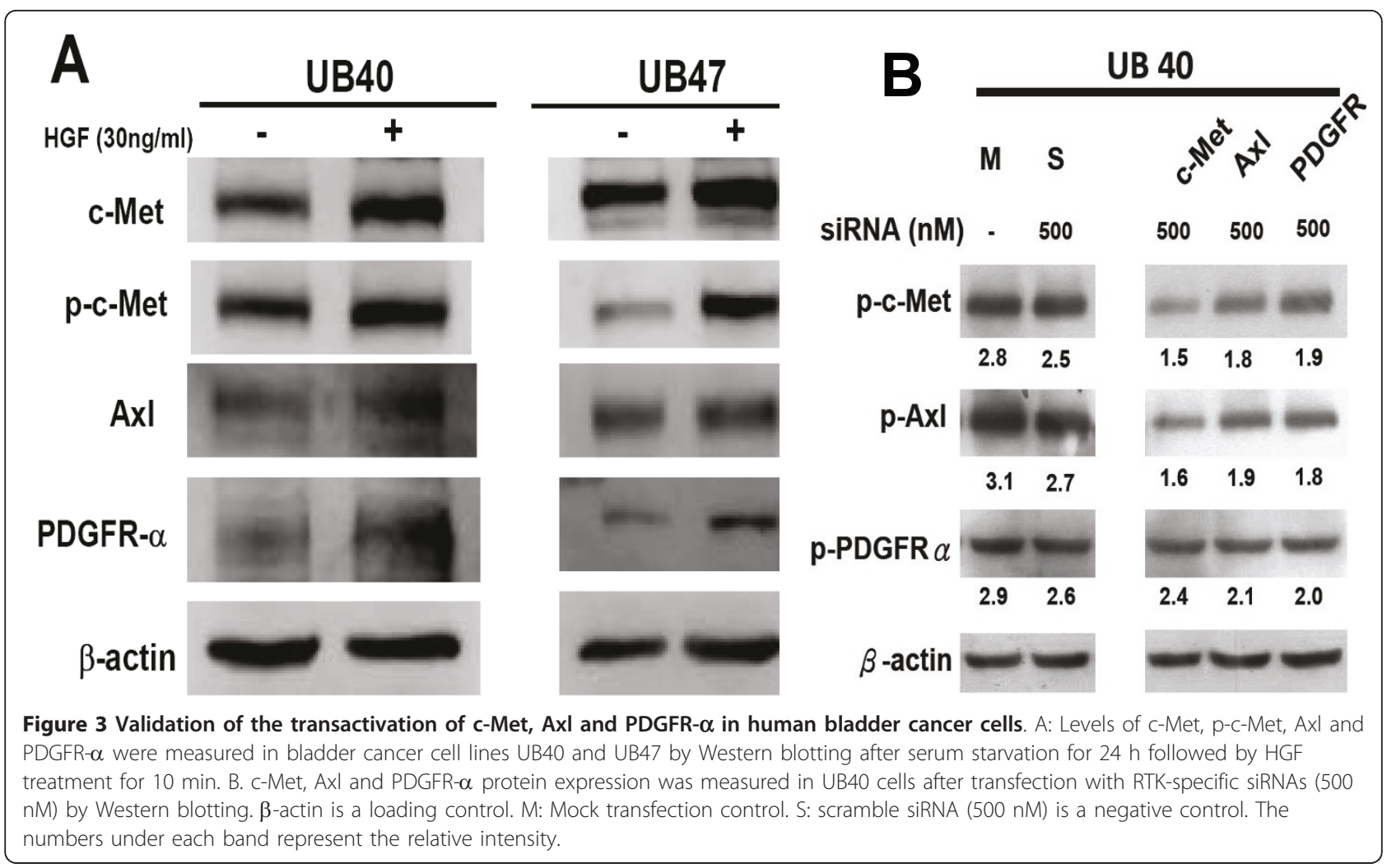

To clarify the interaction among c-Met, Axl and PDGFR- $\alpha$, UB40 cancer cells were transfected with cMet, Axl and PDGFR- $\alpha$ specific siRNAs at the optimal concentrations for $48 \mathrm{~h}$. When expression of each receptor protein was suppressed by their specific siRNA, expression levels of the other two proteins showed a trend of down-regulation, with a higher correlation between c-Met and Axl (Figure 3B). However, co-immunoprecipitation assay did not reveal evidence of direct interaction among these three RTK proteins at cell membrane level (data not shown). Taken together, the above data demonstrate a cross-talk among c-Met, Axl and PDGFR- $\alpha$ in a protein-protein interaction independent manner in human bladder cancer cells.

The involvement of MEK/ERK signaling pathway in the transactivation of Axl and PDGFR- $\alpha$ by c-Met

There are several reports of signaling regulation about RTK transactivation. For example, a HGF-independent activation of c-Met by fibronectin was reported to promote the tumor invasion/metastasis [36]. Through binding to $\alpha_{5} \beta_{1}$-integrin, fibronectin directly associates with c-Met and activates both Src and focal adhesion kinase activity. To clarify the potential involvement of this cMet/Src-related signaling event, the Src inhibitor PP2 (Calbiochem, Merck, Darmstadt, Germany) was used to treat serum starved UB40 cells for $24 \mathrm{~h}$. As shown in
Figure 4A, suppression of Src phosphorylation did not alter the levels of c-Met and Axl, indicating that Src is not involved in the cross-talk of the three RTKs.

It is well known that MEK/ERK $1 / 2$ is one of the most important transducer proteins when HGF binds to c-Met [1]. Both FTI-277 (a Ras farnesylation inhibitor; Calbiochem, San Diego, CA, USA) and PD98059 (a MEK 1 inhibitor; Cashmere Biotech Co., Taipei, Taiwan) were used to verify the involvement of MEK/ERK $1 / 2$ signaling in c-Met-mediated activation of Axl and PDGFR- $\alpha$. We showed that ERK phosphorylation was abrogated by PD98059 after HGF treatment for $24 \mathrm{~h}$ (Figure 4B, lanes 4 and 8) compared to FTI-277 (Figure 4B, lanes 3 and 7), suggesting the existence of a ras-independent phosphorylation of ERK mediated by HGF. The HGF-up-regulated Axl and PDGFR- $\alpha$ could be inhibited by PD98059 (Figure $4 \mathrm{~B}$, lanes 4 and 8 ), supporting the involvement of MEK/ERK $1 / 2$ signaling in this transactivation event. In summary, MEK/ERK $1 / 2$ signaling is involved in the transactivation of Axl and PDGFR- $\alpha$ by HGF/c-Met pathway in human bladder cancer cell lines, but is independent of ras or Src activity.

The effect of cross-talk of c-Met, Axl, and PDGFR- $\alpha$ on cell migration

Upon HGF stimulation, c-Met induces several biological responses that collectively give rise to a program known 


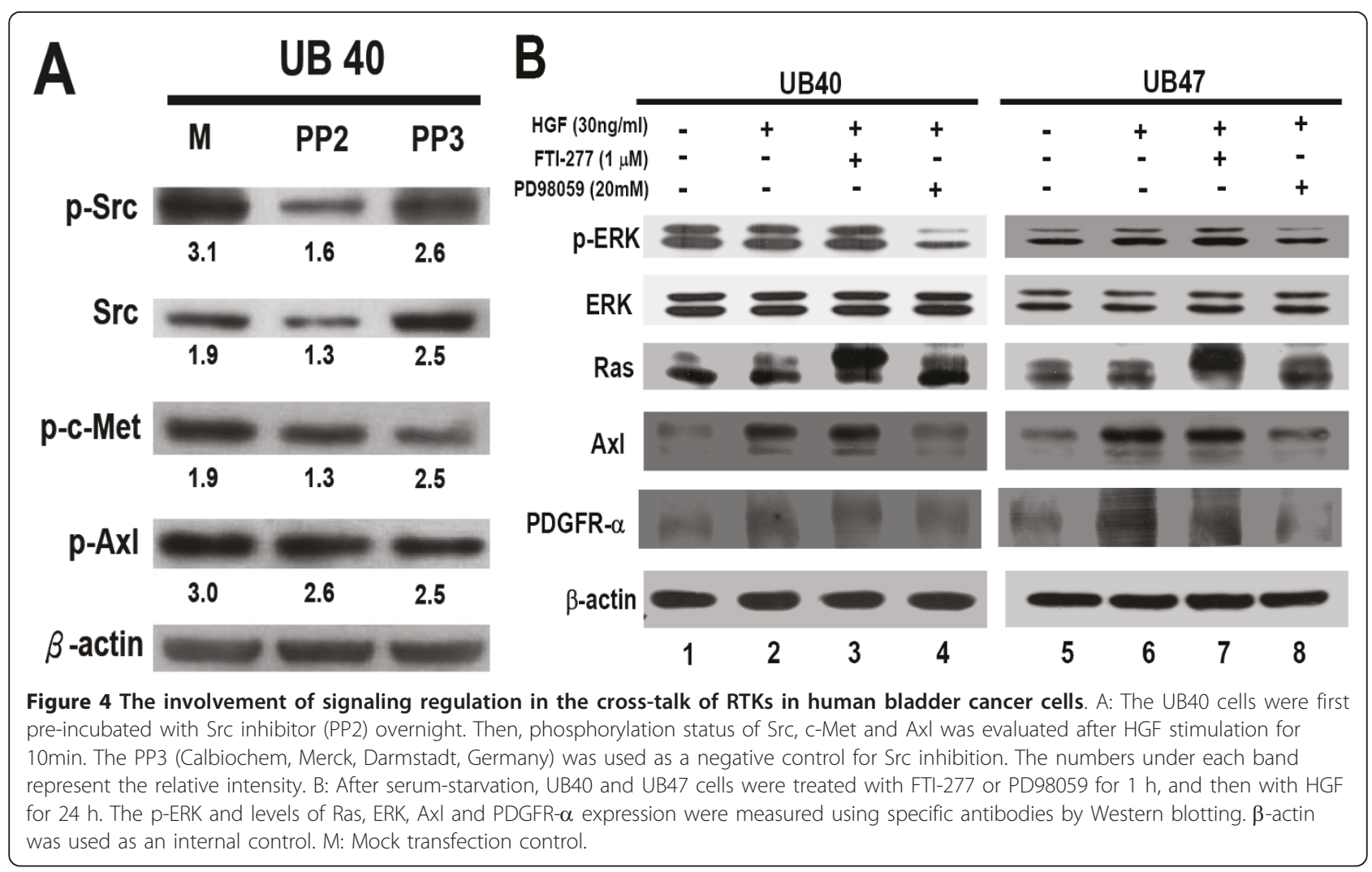

as "invasive growth". To clarify the biological relevance of cross-talk among c-Met, Axl and PDGFR- $\alpha$, cell migration assay was conducted. The transwell experiment showed that migration of TSGH8301 bladder cancer cells was considerably suppressed by c-Met siRNA knock-down $(\mathrm{p}<0.001)$. In addition, apparent inhibition was also demonstrated when shRNA for Axl or PDGFR$\alpha$ alone was treated $(\mathrm{p}<0.01)$ (Figure 5A and 5B). Figure $5 \mathrm{C}$ shows that the siRNA for $\mathrm{c}$-Met and shRNAs for Axl and PDGFR- $\alpha$, TSGH8301, indeed suppressed their target gene expression in TSGH8301 cells. This result is consistent with the reports on Axl in the breast [37] and liver cancers [38], and on the PDGFR- $\alpha$ in liver cancer [39], respectively. Our result suggests that c-Met, Axl and PDGFR- $\alpha$ may induce comparable biological functions, possibly through the same signaling pathway or inter-connecting signal network.

\section{Clinical implication of c-Met, Axl, and PDGFR- $\alpha$ co-} expression patterns in human bladder cancer patients To clarify the clinical implication of the above-mentioned findings in vitro, expression levels of c-Met, Axl and PDGFR- $\alpha$ were examined by immunohistochemistry in a total of 65 cases of locally advanced and metastatic bladder tumors. Co-expression of c-Met/Axl/ PDGFR- $\alpha$ in a case of a bladder cancer tissue was demonstrated in Figure 6. Collectively, overexpression of c-Met, Axl, and PDGFR- $\alpha$ was found in 30 (46.2\%), $52(80 \%)$, and $40(61.5 \%)$ cases, respectively. Coexpression of two receptors was revealed in $22(33.8 \%$, c-Met/Axl), 27 (41.5\%, c-Met/PDGFR- $\alpha$ ), and 17 (26.2\%, Axl/PDGFR- $\alpha$ ) cases. Fourteen cases (21.5\%) showed co-expression of three receptors (c-Met/Axl/ PDGFR- $\alpha$ ). In these human bladder tumors, overexpression of PDGFR- $\alpha$ was correlated with nodal metastasis and overexpression of c-Met or c-Met/Axl/ PDGFR- $\alpha$ showed the most significant correlation with poor patient survival $(p<0.01)$ followed by c-Met/ PDGFR- $\alpha$, PDGFR- $\alpha$, c-Met/Axl, and Axl/PDGFR- $\alpha$ ( $p$ $<0.05$ ) (table 2). Kaplan Meier survival analysis showed that cumulative survival of patients with high expression of c-Met/Axl and c-Met/PDGFR- $\alpha$ was significantly lower than those with lower expression (Log rank test, $p<0.05$ ) (Figure 7A and 7B). After adjusting for nodal status, multivariate analysis using log rank test revealed that indicators associated with poor long term survival were over-expression of $\mathrm{c}$-Met and coexpression of c-Met/Axl/PDGFR- $\alpha(p=0.015)$ (data not shown). We next used a Cox proportional hazards models to determine the relative risk (RR) of overall survival with 95\% confidence interval (CI). The RR of poor long term survival was 3.340 for over-expression of c-Met, and 3.860 for co-expression of c-Met/Axl/ PDGFR- $\alpha$. Taken together, our results indicate that, in 


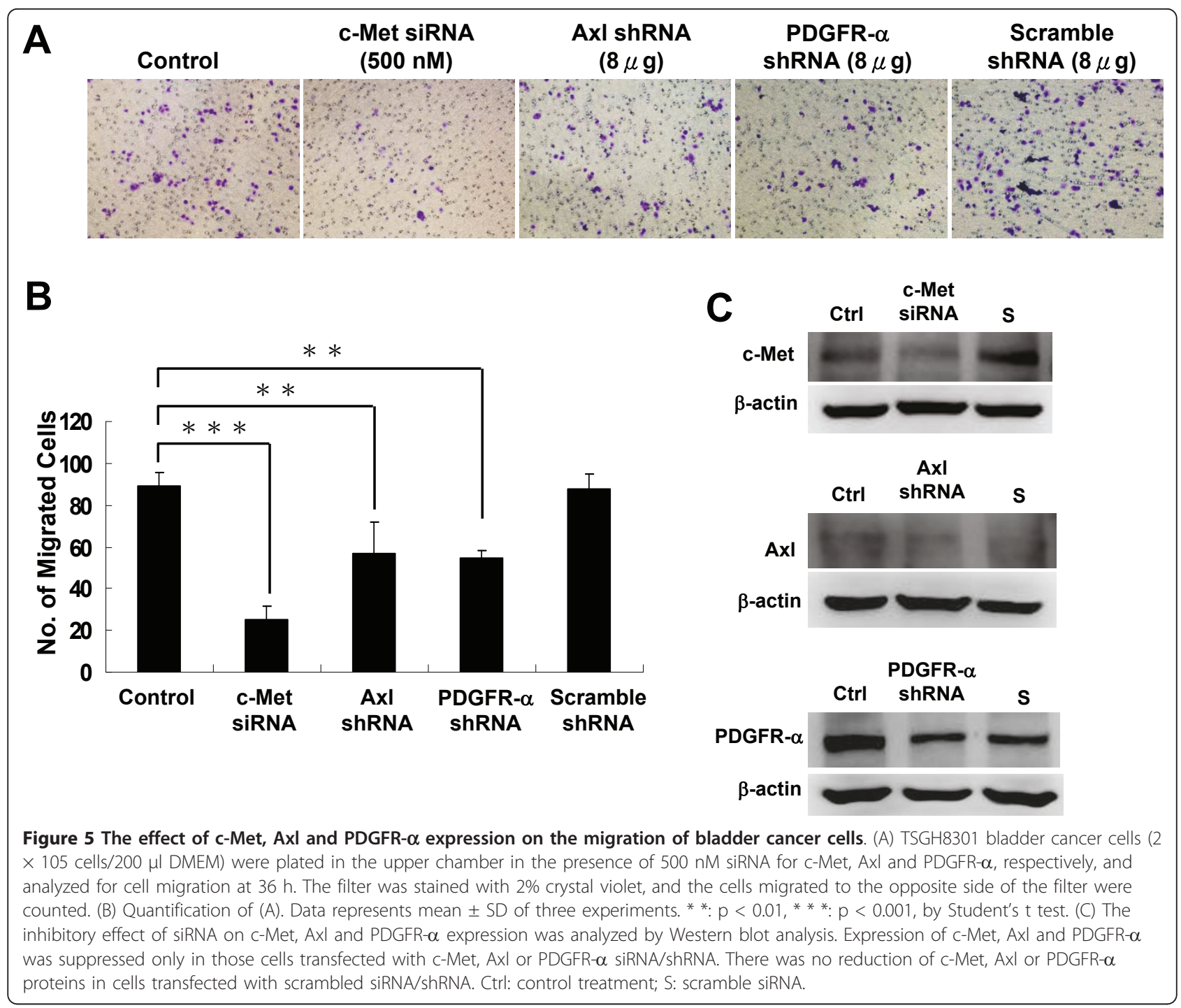

addition to c-Met, both Axl and PDGFR- $\alpha$ play a positive role in the progression of human bladder cancer.

\section{Discussion and conclusions}

In this study, we showed that both Axl and PDGFR- $\alpha$ have a functional interaction with c-Met in vitro and in vivo. This is the first report showing their potential clinical importance in human bladder cancer. The results concur with co-expression of c-Met/PDGFR- $\alpha$ in all of 9 human bladder cancer cell lines reported by Black and his colleagues [40]. The interaction between c-Met and Axl or PDGFR- $\alpha$ was further corroborated by HGF stimulation and siRNA silencing experiments in vitro. The interaction among these three RTKs may be initiated by protein-protein interaction or signaling transduction. The former possibility was excluded by co-immunoprecipitation assay (data not shown). In terms of signal regulation, the successful inhibition of c-Met activation by
PD98059, but not by FTI-277 (ras inhibitor) or PP2 (Src inhibitor), suggests a ras- and Src-independent MEK/ ERK $1 / 2$ signaling in the transactivation of $\mathrm{Axl}$ and PDGFR- $\alpha$. Our results seem to imply the existence of a novel mechanism by which c-Met transactivates the expression of Axl and PDGFR- $\alpha$. Additional experiments are required to clarify whether protein kinase $C$ is involved in this cross-talk in vivo.

Further support for our hypothesis of regulation at transcriptional level comes from several prior reports. The Sp1/Sp3 cis-acting elements were demonstrated to activate the promoter of Axl in various cancer cell lines [41]. Moreover, Sp1 response elements are detected in PDGFR- $\alpha$ promoter region $[42,43]$. Given that c-Met induces the phosphorylation of Sp1 and enhances downstream gene expression through MEK/ERK signaling pathway [44,45], c-Met might up-regulate the expression of Axl and PDGFR- $\alpha$ through Sp1. The dose-dependent 


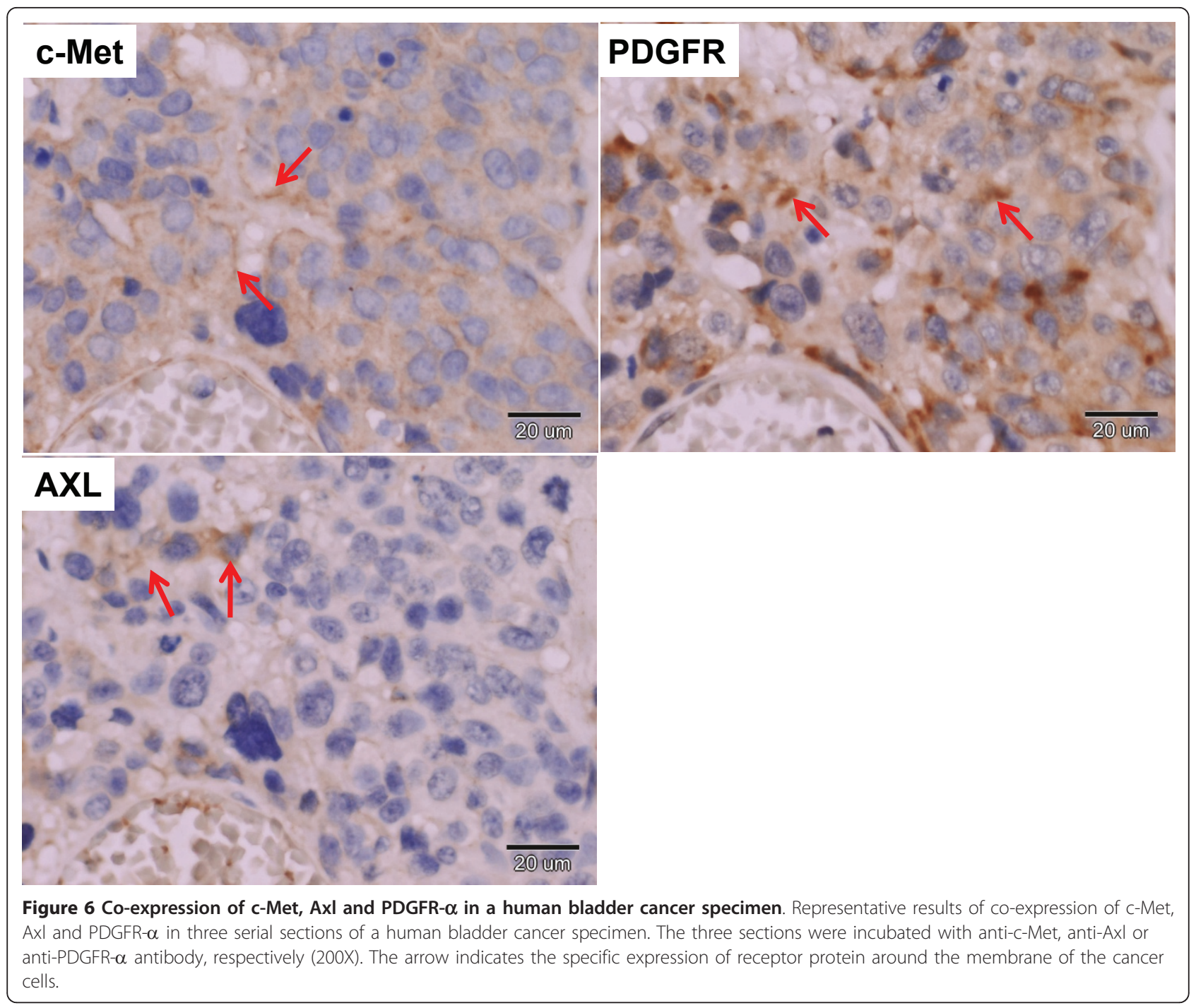

Table 2 Correlation of c-Met, Axl, and PDGFR- $\alpha$ protein expression with clinicopathologic parameters of patients with locally advanced and metastatic bladder cancers

\begin{tabular}{llllll}
\hline Expression pattern & Grade & $\begin{array}{l}\text { T } \\
\text { status* }\end{array}$ & Multiple & $\begin{array}{l}\text { Node } \\
(+)\end{array}$ & Survival \\
\hline c-Met & 0.561 & 0.904 & 0.727 & 0.321 & $0.009^{\dagger}$ \\
Axl & 0.409 & 0.105 & 0.795 & 0.300 & 0.789 \\
PDGFR- $\alpha$ & 0.344 & 0.470 & 0.718 & $0.049^{\dagger}$ & $0.027^{\dagger}$ \\
c-Met \& Axl & 0.140 & 0.070 & 0.277 & 0.061 & $0.031^{\dagger}$ \\
c-Met \& PDGFR- $\alpha$ & 0.184 & 0.686 & 0.957 & 0.802 & $0.011^{\dagger}$ \\
Axl \& PDGFR- $\alpha$ & 0.439 & 0.585 & 0.762 & 0.369 & $0.049^{\dagger}$ \\
c-Met \& AxI \& PDGFR- & 0.595 & 0.377 & 0.346 & 0.281 & $0.008^{\dagger}$ \\
$\alpha$ & & & & & \\
\hline
\end{tabular}

*Statistical analysis was performed between stage pT2 (21), pT3 (27) and stage pT4 (17), according to TNM (2002) classification criteria.

${ }^{+} p$ value less than 0.05 . suppression of Sp1, Axl and PDGFR- $\alpha$ by c-Met siRNA supports our speculation (Additional file 2).

It has been reported that HGF is expressed in fibroblast-like cells, smooth muscle cells, and endothelial cells of the bladder [46]. Expression of c-Met on the cancer cell surface thus may enable the paracrine activation in vivo, irrespective of their capability to synthesize HGF. The correlation of co-expression of two or three of the RTKs with patient survival supports the "invasive growth" program in carcinomas with multiple RTK over-expression $[13,15,47]$. The prognostic significance of c-Met, whether alone or co-expressed with Axl/ PDGFR- $\alpha$, supports the clinical relevance of c-Metdirected therapy (e.g. PHA665752) for human bladder cancer. Since the importance of co-targeting therapy for human bladder cancer having co-expressed RTKs has been demonstrated $[15,47]$, a prospective study is 


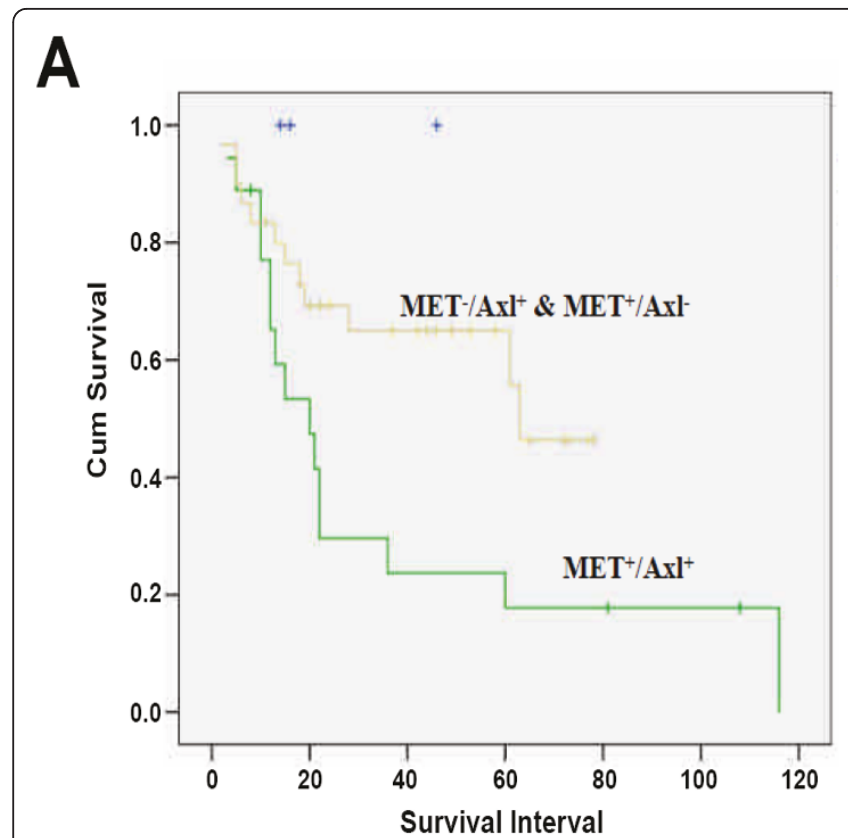

B

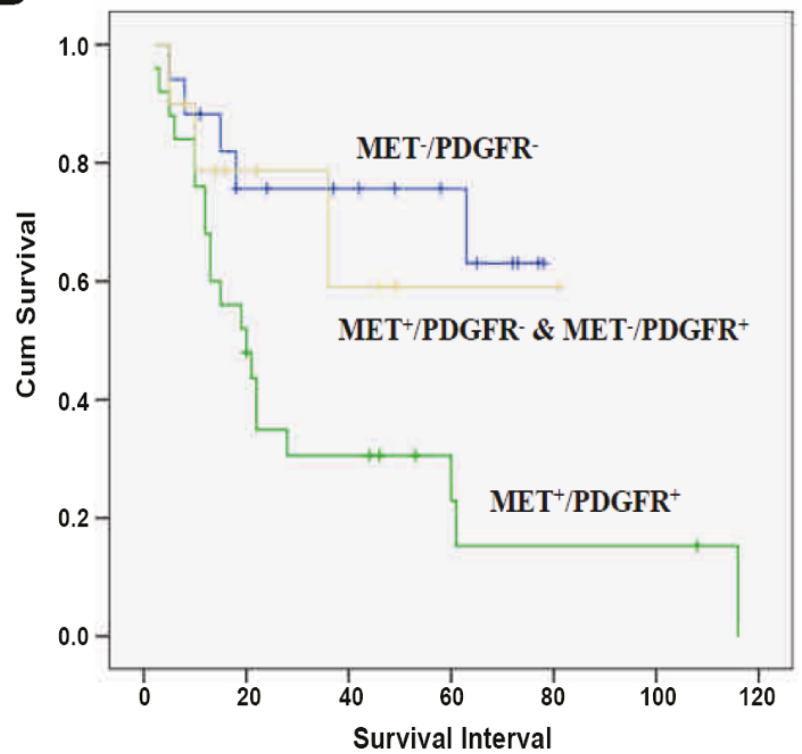

Figure 7 Prognostic significance of co-expression of c-Met and AxI or PDGFR- $\alpha$ in human bladder cancer patients. Kaplan-Meier survival analysis revealed that co-expression of c-Met/Axl (A) or c-Met/PDGFR- $\alpha$ (B) is significantly associated with poor survival in bladder cancer patients than those with single-receptor-positive or no receptor expression ( $p=0.021 \& 0.049$, respectively).

imperative to clarify the significance of Axl and/or PDGFR- $\alpha$ as an additional biomarker or implementation of MEK1/2 inhibitor in the design of c-Met-targeting therapy for human bladder cancer patients.

It is interesting to note that induction of Axl via "kinase switching" confers the Gleevec resistance in relapsed patients with c-Kit- or PDGFR- $\alpha$-driven tumors of the gastrointestinal tract [48]. Therefore, evaluation of RTK expression profile in human cancer may provide signaling network information and help in prediction of potential drug resistance [49]. Olaussen et al. showed that combinations of tyrosine kinase inhibitors could induce a synergistic antitumor effect and thus improve the therapeutic efficacy [50]. When more highly selective or multi-target tyrosin kinase inhibitors become available, the discovery of co-expression of RTKs in cancer cells highlights the necessity for individualized therapies in the future.

\section{Additional material}

Additional file 1: c-Met expression in NIH/3T3 and NIH-Met5 cell lines in the presence or absence of Tet and/or HGF. The cells and the treatment is the same as Figure 1A, except the expression of IgG was shown as the loading control. M: protein marker.

Additional file 2: The relationship among c-Met, Sp1, Axl and PDGFR- $\alpha$ demonstrated by c-Met siRNA. NIH-Met5 cells $\left(1 \times 10^{6} /\right.$ plate $)$ were transfected with c-Met siRNA (250 nM and $500 \mathrm{nM}$ ) for $24 \mathrm{~h}$. Then, cells were harvested and total protein was extracted and analyzed for cMet, Sp1, Axl and PDGFR- $\alpha$ expression by Western blotting. $\beta$-actin was used as the internal control. The numbers under each band represent the relative intensity.

\section{Acknowledgements}

This project was supported by grants of Landmark Project Grant A25 of the National Cheng Kung University funded by the Ministry of Education in Taiwan, 96-2628-B-006-003-MY3 from the National Science Council; and NHRI-EX99-9930BI from the National Health Research Institutes, Taiwan. We thank Dr. R. Zuchini for critical reviewing this manuscript.

\section{Author details}

'Department of microbiology and immunology, College of medicine, National Cheng Kung University, Tainan, Taiwan. ²Department of pathology, College of medicine, National Cheng Kung University, Tainan, Taiwan. ${ }^{3}$ Institute of Basic Medical Sciences, National Cheng Kung University, Tainan, Taiwan. ${ }^{4}$ Department of parasitology, College of medicine, National Cheng Kung University, Tainan, Taiwan. ${ }^{5}$ Department of computer science and information engineering, National Cheng Kung University, Tainan, Taiwan. ${ }^{6}$ Center for gene regulation and signal transduction research, National Cheng Kung University, Tainan, Taiwan. ${ }^{7}$ Graduate Institute of Medical Informatics, Taipei Medical University, Taipei, Taiwan. ${ }^{8}$ Department of Urology, Chia-Yi Christian Hospital, Chia-Yi, Taiwan.

\section{Authors' contributions}

CYT, SMS, and HHY participated in conceptualization, carried out this study, and drafted the manuscript; JWS, YCL, JHC, SMT, GR and TYC participated in the microarray data collection and analysis; $\mathrm{CHS}$ and $\mathrm{NHC}$ provided the clinical specimens; NHC and HSL conceived of the study, and participated in its design and coordination. All authors read and approved the final manuscript

\section{Competing interests}

The authors declare that they have no competing interests.

Received: 25 May 2010 Accepted: 16 April 2011 Published: 16 April 2011 


\section{References}

1. Stuart KA, Riordan SM, Lidder S, Crostella L, Williams R, Skouteris GG: Hepatocyte growth factor/scatter factor-induced intracellular signalling. Int J Exp Pathol 2000, 81(1):17-30.

2. Li B, Kanamaru H, Noriki S, Fukuda M, Okada K: Differential expression of hepatocyte growth factor in papillary and nodular tumors of the bladder. Int J Urol 1998, 5(5):436-440.

3. Peschard P, Park M: From Tpr-Met to Met, tumorigenesis and tubes. Oncogene 2007, 26(9):1276-1285.

4. Wang R, Ferrell LD, Faouzi S, Maher JJ, Bishop JM: Activation of the Met receptor by cell attachment induces and sustains hepatocellular carcinomas in transgenic mice. J Cell Biol 2001, 153(5):1023-1034.

5. Cheng HL, Trink B, Tzai TS, Liu HS, Chan SH, Ho CL, Sidransky D, Chow NH: Overexpression of c-met as a prognostic indicator for transitional cell carcinoma of the urinary bladder: a comparison with p53 nuclear accumulation. J Clin Oncol 2002, 20(6):1544-1550.

6. Cheng HL, Liu HS, Lin YJ, Chen HH, Hsu PY, Chang TY, Ho CL, Tzai TS, Chow NH: Co-expression of RON and MET is a prognostic indicator for patients with transitional-cell carcinoma of the bladder. Br J Cancer 2005, 92(10):1906-1914.

7. Miyata Y, Sagara Y, Kanda S, Hayashi T, Kanetake H: Phosphorylated hepatocyte growth factor receptor/c-Met is associated with tumor growth and prognosis in patients with bladder cancer: correlation with matrix metalloproteinase-2 and -7 and E-cadherin. Hum Pathol 2009, 40(4):496-504.

8. Capdeville R, Buchdunger E, Zimmermann J, Matter A: Glivec (STI571, imatinib), a rationally developed, targeted anticancer drug. Nat Rev Drug Discov 2002, 1(7):493-502.

9. Dussault I, Bellon SF: From concept to reality: the long road to c-Met and RON receptor tyrosine kinase inhibitors for the treatment of cancer. Anticancer Agents Med Chem 2009, 9(2):221-229.

10. Puri N, Khramtsov A, Ahmed S, Nallasura V, Hetzel JT, Jagadeeswaran R, Karczmar G, Salgia R: A selective small molecule inhibitor of c-Met, PHA665752, inhibits tumorigenicity and angiogenesis in mouse lung cancer xenografts. Cancer Res 2007, 67(8):3529-3534.

11. Heldin $\mathrm{CH}$ : Dimerization of cell surface receptors in signal transduction. Cell 1995, 80(2):213-223.

12. Chen Q, Seol DW, Carr B, Zarnegar R: Co-expression and regulation of Met and Ron proto-oncogenes in human hepatocellular carcinoma tissues and cell lines. Hepatology 1997, 26(1):59-66.

13. Chow NH, Chan SH, Tzai TS, Ho CL, Liu HS: Expression profiles of ErbB family receptors and prognosis in primary transitional cell carcinoma of the urinary bladder. Clin Cancer Res 2001, 7(7):1957-1962.

14. Maggiora P, Lorenzato A, Fracchioli S, Costa B, Castagnaro M, Arisio R, Katsaros D, Massobrio M, Comoglio PM, Flavia Di Renzo M: The RON and MET oncogenes are co-expressed in human ovarian carcinomas and cooperate in activating invasiveness. Exp Cell Res 2003, 288(2):382-389.

15. Hsu PY, Liu HS, Cheng HL, Tzai TS, Guo HR, Ho CL, Chow NH: Collaboration of RON and epidermal growth factor receptor in human bladder carcinogenesis. J Urol 2006, 176(5):2262-2267.

16. Jo M, Stolz DB, Esplen JE, Dorko K, Michalopoulos GK, Strom SC: Cross-talk between epidermal growth factor receptor and c-Met signal pathways in transformed cells. J Biol Chem 2000, 275(12):8806-8811.

17. Chow NH, Trink B, Eisenberger C, Sidransky D: Tyrosine kinase profile of bladder cancer. J Urol 1998, 159:1096.

18. Meric F, Lee WP, Sahin A, Zhang H, Kung HJ, Hung MC: Expression profile of tyrosine kinases in breast cancer. Clin Cancer Res 2002, 8(2):361-367.

19. Wu CW, Li AF, Chi CW, Lai CH, Huang CL, Lo SS, Lui WY, Lin WC: Clinical significance of AXL kinase family in gastric cancer. Anticancer Res 2002, 22(2B):1071-1078.

20. Chung BI, Malkowicz SB, Nguyen TB, Libertino JA, McGarvey TW: Expression of the proto-oncogene $\mathrm{Axl}$ in renal cell carcinoma. DNA Cell Biol 2003, 22(8):533-540.

21. Shieh YS, Lai CY, Kao YR, Shiah SG, Chu YW, Lee HS, Wu CW: Expression of axl in lung adenocarcinoma and correlation with tumor progression. Neoplasia 2005, 7(12):1058-1064.

22. Sainaghi PP, Castello L, Bergamasco L, Galletti M, Bellosta P, Avanzi GC: Gas6 induces proliferation in prostate carcinoma cell lines expressing the Axl receptor. J Cell Physiol 2005, 204(1):36-44.

23. Carvalho I, Milanezi F, Martins A, Reis RM, Schmitt F: Overexpression of platelet-derived growth factor receptor alpha in breast cancer is associated with tumour progression. Breast Cancer Res 2005, 7(5): R788-795.

24. Dabrow MB, Francesco MR, McBrearty FX, Caradonna S: The effects of platelet-derived growth factor and receptor on normal and neoplastic human ovarian surface epithelium. Gynecol Oncol 1998, 71(1):29-37.

25. Fudge $K$, Bostwick DG, Stearns ME: Platelet-derived growth factor A and $B$ chains and the alpha and beta receptors in prostatic intraepithelial neoplasia. Prostate 1996, 29(5):282-286.

26. Stock P, Monga D, Tan X, Micsenyi A, Loizos N, Monga SP: Platelet-derived growth factor receptor-alpha: a novel therapeutic target in human hepatocellular cancer. Mol Cancer Ther 2007, 6(7):1932-1941.

27. Tawfik OW, Kramer B, Shideler B, Danley M, Kimler BF, Holzbeierlein J: Prognostic significance of CD44, platelet-derived growth factor receptor alpha, and cyclooxygenase 2 expression in renal cell carcinoma. Arch Pathol Lab Med 2007, 131(2):261-267.

28. Donnem T, Al-Saad S, Al-Shibli K, Andersen S, Busund LT, Bremnes RM: Prognostic impact of platelet-derived growth factors in non-small cell lung cancer tumor and stromal cells. J Thorac Oncol 2008, 3(9):963-970.

29. Lin YS, Su LJ, Yu CT, Wong FH, Yeh HH, Chen SL, Wu JC, Lin WJ, Shiue YL, Liu HS, et al: Gene expression profiles of the aurora family kinases. Gene Expr 2006, 13(1):15-26.

30. Chang TY, Wen YY, Yeh HH, Wang ST, Su IJ, Liu HS: Plasmid harboring lac repressor and tTA activator genes can regulate two inducible genes in mammalian cells. Biotechniques 1999, 27(3):466-469.

31. Robinson DR, Wu YM, Lin SF: The protein tyrosine kinase family of the human genome. Oncogene 2000, 19(49):5548-5557.

32. Novoradovskaya N, Whitfield ML, Basehore LS, Novoradovsky A, Pesich R, Usary J, Karaca M, Wong WK, Aprelikova O, Fero M, et al: Universal Reference RNA as a standard for microarray experiments. BMC Genomics 2004, 5(1):20.

33. Ben-Dor A, Shamir R, Yakhini Z: CAST - Clustering Affinity Search Technique. J Comput Biol 1999, 6:281-297.

34. Eble JNSG, Epstein J, Sesterhenn IA, (Eds): Multilocular cystic renal cell carcinoma In: World Health Organization Classification of Tumours. Pathology and Genetics of Tumours of the Urinary System and Male Genital Organs 2004, 26

35. Chen CC, Shieh B, Jin YT, Liau YE, Huang CH, Liou JT, Wu LW, Huang W, Young KC, Lai MD, et al: Microarray profiling of gene expression patterns in bladder tumor cells treated with genistein. J Biomed Sci 2001 8(2):214-222.

36. Mitra AK, Sawada K, Tiwari P, Mui K, Gwin K, Lengyel E: Ligandindependent activation of c-Met by fibronectin and alpha(5)beta(1)integrin regulates ovarian cancer invasion and metastasis. Oncogene 2010, 30(13):1566-1576.

37. Vuoriluoto K, Haugen H, Kiviluoto S, Mpindi JP, Nevo J, Gjerdrum C, Tiron C, Lorens JB, Ivaska J: Vimentin regulates EMT induction by Slug and oncogenic H-Ras and migration by governing Axl expression in breast cancer. Oncogene 2010, 30(12):1436-1448.

38. He L, Zhang J, Jiang L, Jin C, Zhao Y, Yang G, Jia L: Differential expression of $\mathrm{Axl}$ in hepatocellular carcinoma and correlation with tumor lymphatic metastasis. Mol Carcinog 2010, 49(10):882-891.

39. Gotzmann J, Fischer AN, Zojer M, Mikula $M$, Proell $V$, Huber $H_{\text {, Jechlinger } M}$ Waerner T, Weith A, Beug $H$, et al: A crucial function of PDGF in TGF-betamediated cancer progression of hepatocytes. Oncogene 2006, 25(22):3170-3185.

40. Black PC, Brown GA, Inamoto T, Shrader M, Arora A, Siefker-Radtke AO, Adam L, Theodorescu D, Wu X, Munsell MF, et al: Sensitivity to epidermal growth factor receptor inhibitor requires $\mathrm{E}$-cadherin expression in urothelial carcinoma cells. Clin Cancer Res 2008, 14(5):1478-1486.

41. Mudduluru G, Allgayer $H$ : The human receptor tyrosine kinase Axl genepromoter characterization and regulation of constitutive expression by Sp1, Sp3 and CpG methylation. Biosci Rep 2008, 28(3):161-176.

42. Bonello MR, Khachigian LM: Fibroblast growth factor-2 represses plateletderived growth factor receptor-alpha (PDGFR-alpha) transcription via ERK1/2-dependent Sp1 phosphorylation and an atypical cis-acting element in the proximal PDGFR-alpha promoter. J Biol Chem 2004, 279(4):2377-2382.

43. Kawagishi J, Kumabe T, Yoshimoto T, Yamamoto T: Structure, organization, and transcription units of the human alpha-platelet-derived growth factor receptor gene, PDGFRA. Genomics 1995, 30(2):224-232. 
44. Paumelle R, Tulasne D, Kherrouche Z, Plaza S, Leroy C, Reveneau S, Vandenbunder B, Fafeur V: Hepatocyte growth factor/scatter factor activates the ETS1 transcription factor by a RAS-RAF-MEK-ERK signaling pathway. Oncogene 2002, 21(15):2309-2319.

45. Reisinger K, Kaufmann R, Gille J: Increased Sp1 phosphorylation as a mechanism of hepatocyte growth factor (HGF/SF)-induced vascular endothelial growth factor (VEGF/VPF) transcription. J Cell Sci 2003, 116(Pt 2):225-238.

46. Joseph A, Weiss GH, Jin L, Fuchs A, Chowdhury S, O'Shaugnessy P, Goldberg ID, Rosen EM: Expression of scatter factor in human bladder carcinoma. J Natl Cancer Inst 1995, 87(5):372-377.

47. Su L, Hsu SL, Yang JS, Tseng HH, Huang SF, Huang CY: Global gene expression profiling of dimethylnitrosamine-induced liver fibrosis: from pathological and biochemical data to microarray analysis. Gene Expr 2006, 13(2):107-132.

48. Mahadevan D, Cooke L, Riley C, Swart R, Simons B, Della Croce K, Wisner L, lorio $M$, Shakalya $K$, Garewal $H$, et al: A novel tyrosine kinase switch is a mechanism of imatinib resistance in gastrointestinal stromal tumors. Oncogene 2007, 26(27):3909-3919.

49. Rikova K, Guo A, Zeng Q, Possemato A, Yu J, Haack H, Nardone J, Lee K, Reeves C, Li Y, et al: Global survey of phosphotyrosine signaling identifies oncogenic kinases in lung cancer. Cell 2007, 131(6):1190-1203.

50. Olaussen KA, Commo F, Tailler M, Lacroix L, Vitale I, Raza SQ, Richon C, Dessen P, Lazar V, Soria JC, et al: Synergistic proapoptotic effects of the two tyrosine kinase inhibitors pazopanib and lapatinib on multiple carcinoma cell lines. Oncogene 2009, 28(48):4249-4260.

\section{Pre-publication history}

The pre-publication history for this paper can be accessed here: http://www.biomedcentral.com/1471-2407/11/139/prepub

doi:10.1186/1471-2407-11-139

Cite this article as: Yeh et al:: Transcriptional activation of the Axl and PDGFR- $\alpha$ by c-Met through a ras- and Src-independent mechanism in human bladder cancer. BMC Cancer 2011 11:139.

\section{Submit your next manuscript to BioMed Central and take full advantage of:}

- Convenient online submission

- Thorough peer review

- No space constraints or color figure charges

- Immediate publication on acceptance

- Inclusion in PubMed, CAS, Scopus and Google Scholar

- Research which is freely available for redistribution

Submit your manuscript at www.biomedcentral.com/submit 